\title{
Gymnema sylvestre a- Potential Inhibitor of COVID-19 Main Protease by MD simulation Study
}

\author{
Senthil Kumar Subramani, ${ }^{1,}$, Yash Gupta ${ }^{3}$, Manish $^{4}$, GBKS Prasad ${ }^{2 *}$ \\ ${ }^{1}$ Department of Biotechnology, Tropilite Bioscience Pvt. Ltd., Gwalior, India. \\ ${ }^{2}$ Centre for Translational Research, SOS in Biochemistry Jiwaji University, Gwalior, India. \\ ${ }^{3}$ Loyola University Chicago Stritch School of Medicine, Chicago, IL, 60153, USA. \\ ${ }^{4}$ School of Computational and Integrative Sciences, Jawaharlal Nehru University, New Delhi, \\ India. \\ *Corresponding author: gbksprasad@gmail.com
}

\section{Abstract:}

The crystal structure of the main protease $\left(\mathrm{M}^{\text {pro }}\right)$ for SARS-CoV-2, recently had been made available. This $\mathrm{M}^{\mathrm{pro}}$ is 3-chymotrypsin-like cysteine protease $\left(3 \mathrm{CL}^{\mathrm{pro}}\right)$ is significantly identical to the previously published SARS-CoV. It is essential for viral replication; because of this, it is a potential drug target. Now scientists around the world are searching for an inhibitor of this enzyme from both synthetic and natural substances. Herbal plants produce different kinds of bioactive compounds, making them a rich source of various types of medicines and used in multiple targeting the particular disease, Gymnema sylvestre $(G S)$ is the one of the herbal plant used since in ancient times. The present study aimed to assess bioactive compounds GS mainly gymnemic acids as potential inhibitors for COVID-19 against $\mathrm{M}^{\text {pro }}$ enzyme using a molecular docking study. The docking score observed between -53.4 to -42.4 of all gymnemic acids and its derivatives. Molecular Dynamics (MD) simulation studies carried out at 100ns supported the stability of GS molecules within the binding pocket. RMSD score of less than 3.6. mainly, our results supported that these GS molecules bind to the domain I \& II, and domain II-III linker of $3 \mathrm{CL}^{\text {pro }}$ enzyme, suggesting its suitability as strong candidate for therapeutic against COVID-19.

\section{Significant:}

In this current scenario, our study result given big lead to the antiviral therapy. Based on MD simulation it shows the good stability with protein molecule and it inhibits the substrate binding site.GS is currently used many people mainly for anti diabetic therapy, so it can be used COVID19 without any further delay. However, the dosage has to be standardized.

Keywords: COVID-19, SARS-CoV-2, Main protease, Gymnema sylvestre, Gymnemic acids, Molecular docking and Molecular Dynamics simulation.

\section{Introduction:}

Currently, the world is experiencing an unprecedented life threatening highly contagious SARS-CoV-2 infection without specific anti-viral therapy in vision. The virus is spreading logarithmically and efforts to develop of new therapeutics is essential till an effective evidence based therapy is available.

Coronaviruses $(\mathrm{CoV})$ are a large group of enveloped viruses with a positive-sense singlestranded RNA genome and a nucleocapsid of helical symmetry (Woo et al., 2010) with protein spikes appearing like a crown, which means "corona" in Latin.(Pene et al., 2003). In humans, it 
causes respiratory syndrome that can range from a common cold to lung and multi-organ failure. The infection due to SARS-CoV2 remains mild in most of the cases.(Fehr \& Perlman, 2015; Herrewegh et al., 1998), however, some of the viruses this family cause lethal infection like SARS-CoV (Severe Acute Respiratory Syndrome), and MERS-CoV(Middle East Respiratory Syndrome)(Assiri et al., 2016; Luhulima et al., 2016). These viruses are believed to be bat-borne in nature and circulate in a range of animals and transmitted to humans(Yang et al., 2015). The SARS-CoV2 infection was first surfaced in China when a cluster of pneumonia cases was reported in a group of people consuming seafood and livestock markets in China in midDecember 2019(Chan et al., 2020; J. Y. Li et al., 2020).

Eventually the outbreak was linked to a novel CoV related to the SARS CoV based on the similarities in the genetic material (Lu et al., 2020). Later, the disease was reported to be caused by SARS-CoV2 and was named as COVID-19 by World Health Organization (WHO) (WHO, 2020b). The outbreak started in China rapidly escalated to all over the world. It is estimated that there are around 4.73 million COVID -19 cases, and 3.16 lakhs deaths around the world as on $19^{\text {th }}$ May ,2020(WHO, 2020a). It is said that there are probably an important number of asymptomatic carriers in the population, but not diagnosed and thus the mortality rate is predicted to be much higher than anticipated. The more rapid spread of COVID19 to different continents is because of globalization and the virus virulence is too high compared to other viruses in this group. Major symptoms of this disease includes high fever, and respiratory symptoms (i.e. cough and shortness of breath) whereas in severe cases pneumonia and kidney failure are a major causes for the death (Huang et al., 2020). Although, nucleic acid based diagnostic tools are available for COVID-19 disease(Corman et al., 2020; Yan Li \& Xia, 2020; Z. Li et al., 2020), vaccines and SARS-CoV-2 specific therapeutic treatments are far from distance(Amanat \& Krammer, 2020; Chhikara et al., 2020).

The 3D crystal structure of SARS-CoV-2 main protease also called 3CL pro, with unliganded active site was released recently.(Owen et al., 2020) 3CL pro enzyme of SARS-CoV-2 processes polyproteins by proteolytic action of replicase enzyme (pp1a and pplab) to release the functional polypeptide. It is a dimeric protein that contains two asymmetric units designated as protomers. Each protomer consists of three domains, namely domain I (residues 8-101), domain II (residues 102-184), and domain III (residues 201-303). Domain III contains five $\alpha$-helices, and it linked to domain II through an extended loop region (residues 185-200). The 3CLpro has a Cys_145 and His_41 catalytic dyad and the substrate-binding site located in a cleft between domains I and II (Fig:1). These properties are identical to the protein structures of SARS-CoV previously published.(Anand et al., 2003; Wang et al., 2016; Yang et al., 2015; Zhao et al., 2008) SARS-CoV-2 3CL ${ }^{\text {pro }}$ is conserved, share $96 \%$ sequence identity with SARS-CoV 3CL ${ }^{\text {pro }}$ and it has some point-mutations in the structure which disrupt important hydrogen bonds and alter the receptor binding site of SARS-CoV-2 3CL ${ }^{\text {pro }}$ (ul Qamar et al., 2020). The 3CL pro of SARS-CoV-2 is an attractive drug target for antiviral drug candidates. Some of the studies are done on synthetic compound and natural compound through virtually screening for fast identification of drug candidates against SARS-CoV-2. (Das et al., 2020; Gul et al., 2020; Kumar et al., 2020; Maurya $\&$ Sharma, 2020). Some of the bioactive molecules from natural products are also shown good inhibitory effect against SARS-CoV-2 in in silico studies.(Khaerunnisa et al., 2020)

Gymnema sylvestre (GS) is in use in India as traditional herb for over 2000 years to treat diabetes(Mahajan et al., 2015). This a widely studies medicinal plant for anti viral activity (Rao et al., 1974), anti-ulcer, anti-stress, anti-allergic (Arun et al., 2014), anti-inflammations(Malik et 
al., 2008) immunomodulatory (Singh et al., 2015) anti-tumour (Yasukawa et al., 2014), antimicrobial(Arora \& Sood, 2017), antioxidant(Kang et al., 2012) hepato protective functions (Komalavalli \& Rao, 2000). The G. sylvestre has possess many bioactive compounds (Table:1) Gymenimic acids are the major bioactive compounds present in this plant and found in all parts of the plant (H.-M. Liu et al., 1992). However the young leaf has high concentration of gymnemic acids(Manohar et al., 2009), and Gymnemagenin (Kamble et al., 2013; Raju et al., 2006). In this study we explored in silico, inhibitory activity of the gymnemic acid and its derivatives against SARS-CoV-2 3CL ${ }^{\text {pro }}$ using Molecular docking and molecular dynamics (MD) simulation.

\section{Methodology:}

\section{Ligand preparation.}

The structures of reported bioactive compounds of $G$. sylvestre from Pubchem/ ChemSpider (http://www.chemspider.com/), energy were minimized using Avogadro software (Hanwell et al., 2012) and converted into PDB format. (Detailed structures are given in Table: 2)

\section{ADME Calculations.}

Swiss ADME(Daina et al., 2017)and PKCSM(Pires et al., 2015) were used to calculate ADMET (i.e. Absorption, Distribution, Metabolism, Excretion, and Toxicity) profile of GS molecule and the results are shown in Table: 2 .

\section{Protein preparation.}

The protease structure, 3-chymotrypsin-like cysteine protease $\left(3 \mathrm{CL}^{\mathrm{pro}}\right)$ enzyme of SARSCoV-2 (PDB ID: 6y84) with $2.1 \AA$ was downloaded from the protein databank (www.rcsb.org/pdb) and the hetero atoms were removed by using discovery studio visuvilizear before the docking analysis.

\section{Docking analysis.}

PatchDock: The bioactive compounds of $G$. sylvestre were docked with $3 \mathrm{CL}^{\text {pro }}$ in silico by submitting the structures to the PatchDock server (http://bioinfo3d.cs.tau.ac.il/ PatchDock/), which is based on shape complimentarily principles(Schneidman-Duhovny et al., 2005).

FireDock: The Patch Dock results were resubmitted for refinement using the Fire Dock server (http://bioinfo3d.cs.tau.ac.il/FireDock/), which rearranges the interface side chains and adjusts the relative orientation of the molecules (Andrusier et al. 2007; Mashiach et al. 2008).

Acceryls discovery studio visualize (2016): $\quad$ A comprehensive software suite includes functionality for viewing and editing tools for performing basic data analysis. It was downloaded from http://accelrys.com/products/ collaborativescience/biovia-discovery-studio/visualizationdownload.php.

\section{Simulation.}

Extensive 100ns MD simulation carried out on the complex structure of 6y84 receptor with GMG molecule using Desmond software to access the binding stability of the GMG-6y84 complex(Schrödinger Release, 2019). The system was solvated in TIP3P water model and 0.15 M $\mathrm{NaCl}$ to mimic a physiological ionic concentration. The full system energy minimization step was done for $100 \mathrm{ps}$. The MD simulation was run for $100 \mathrm{~ns}$ at $300 \mathrm{~K}$ temperature, standard pressure(1.01bar), within an orthorhombic box $10 \AA$ and NPT ensemble. The energy (kcal/mol) was recorded at an interval of 1.2 ps. The protein-ligand complex system was neutralized by balancing the net charge of the system by adding $\mathrm{Na}+$ or $\mathrm{Cl}$ - counter ions. 


\section{Results:}

\section{ADME properties.}

The drug likeliness and ADME properties were evaluated for the GS compounds and results were obtained for different models. The bioavailability score was high for GMG (0.17) may be due to the less TPA(121) and molecular weight (506.7) compared to the other molecule, $\mathrm{CaCo} 2$ permeability less, all the GS compounds do not have any toxicity (details are given in Table:2 )

\section{Molecular docking.}

This docking study showed the GS molecules have good interaction with SARS-CoV-2 $3 \mathrm{CL}^{\mathrm{pro}}$ leading to its inhibition. GA3 showed high binding energy of $-52.46 \mathrm{Kcal} / \mathrm{mol}$ with -23.77 , 5.18 of attractive and repulsive Van der Waals energy respectively. GA3 forms hydrogen bonds at amino acid residues such LEU_27,HIS_41,GLY_143 CYS_145, HIS_164, PRO_168, ARG_188, GLN_189, THR_190, ALA_191, GLN192 and the hydrophobic bonds with MET_49, MET_165, LEU_167 the detailed type of bond are given in Table:3 and 3D, 2D image given in Fig:2a.

GA4 has the allosteric binding with the 3CLpro, GA4 was not exactly bound Cys_145 and His_41 catalytic dyad, however, it binds with a pocket molecule which could affect the substrate binding to the domain, GA4 showed the $-52.17 \mathrm{Kcal} / \mathrm{mol}$ binding energy with $-27.15,19.82$ of attractive and repulsive Van der Waals energy respectively. forms hydrogen bonds at amino acid residues such THR_24, THR_26 ,THR_44, THR_45 HIS_164,MET-165 GLU_166,LEU_167 GLU_189, THR_190, GLN_192and the hydrophobic bonds with HIS-14,MET-49 (Table:3,Fig:2b.)

DGA also has the allosteric binding with the 3CLpro like GA4 but the interacting amino acids are different GLU_166, THR_24, THR_190, GLN_192 with hydrogen bonding and HIS14, MET-49, MET 165 hydrophobic bonding was observed, the binding energy DGA was -43.43 $\mathrm{Kcal} / \mathrm{mol}$, attractive and repulsive Van der Waals energy was observed -23.96 and 16.47 respectively. GA3, 4 and DGA have the interacting with linkage amnio acids (Table:3, Fig:2c)

GMG, smallest legend in this study showed binding energy of $-43.69 \mathrm{Kcal} / \mathrm{mol}$ with 19.20, 4.81 of attractive and repulsive Van der Waals energy respectively. The GMG molecule was interacting with this amino acids THR_25, THR_ 26 HIS _41, CYS_44, THR_45, GLN89, LEU 167 by hydrogen bonding and MET_49, MET_165, PRO_168 with hydrophobic bonding. Based on the ADME properties only GMG molecule was taken for the MD simulation.(Table:3,Fig 2 d )

\section{Simulations.}

MD Simulations were carried out to determine the stability of the interactions of GMG molecule with 3CLpro docked complexes for up to $100 \mathrm{~ns}$. The final structure of simulated residues exhibited proper stereochemical geometry, as analyzed by the Ramachandran map 
(Fig:1b). Root Mean Square Deviation (RMSD) change for C $\alpha$, backbone, side-chain, heavy atom and ligfit protein also monitored. This parameter measures the global deviation of atoms during the stimulation. The RMSD plot indicated the fluctuations in the initial conformation of the receptor for all three systems till $20 \mathrm{~ns}$ (Fig. 3a), which later stabilized in production phase with an average value of RMSDC $\alpha$ (1.993 $\AA$ ), RMSD backbone (2.015 $\AA$ ), RMSD side-chain (2.876 $\AA$ ), RMSD heavy atom, and RMSD lig fint protein and for GMG-3CLpro complex. The RMSD of both $\mathrm{C} \alpha$ and backbone for GMG-3CLpro showed fluctuations between the range of $0.8-2.6 \AA$. Protein-RMSF monitored to assess the local residue flexibility (Fig.3b) GMG shown the hydrogen bond interacted with amnion acid THR_24, THR_26,GLU_166,LEU_167, and PRO_168 in the absence of water molecule (Fig.2d). However, in the presence of the water molecule, in strong interaction only with HIS_41 in the pocket atom other 2 strong interaction was observed in the connecting molecules GLN_189, GLN_192 during MD simulation. There are around $20 \mathrm{H}$-bond-water interactions observed. This observation showed the importance of water molecules within the binding pocket of protein 3CLpro for GMG. (Fig 4a.) The total number of contacts formed by protein with the GMG throughout the trajectory presented in the top panel and the bottom panel (Fig. 4b) that showed the residues interacted with the ligand in each trajectory frame.

Six properties were analyzed to explain the stability of the GMG in the $3 \mathrm{CL}^{\text {pro }}$ receptor during the simulation I) ligand RMSD from the graph, it is evident that ligand RMSD remains constant during the simulation process. The overall RMSD of the GMGwas up to $0.8 \AA$. II)

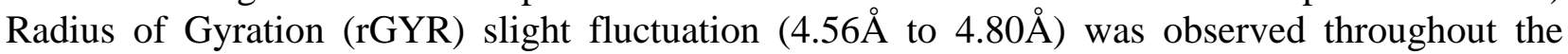
simulation. III) Intramolecular hydrogen bonding (intraHB) was observed throughout the study. IV) Molecular Surface Area (MolSA) slight fluctuation (between400 to $415 \AA^{2}$ ) was observed throughout the simulation V)Accessible Surface Area (SASA) plots also indicated the slight fluctuation between 160 to $320 \AA^{2}$.VI) Polar Surface Area (PSA) - Solvent accessible surface area was observed stable between 205 to $215 \AA^{2}$ after 10 ns. (Fig:5a). The rotatable torsional bond of GMG was assisted by a dial (radial) and bar plots of the same color. The radial and bar diagram clarified the possible torsion relationships and the conformational strain of GMG undergoing the stabilization of protein-bound conformation (Fig:5b).A movie of $100 \mathrm{~ns}$ simulation was also available as supplementary data at YouTubehttps://youtu.be/8FnicM7GF-4.

\section{Discussion:}

COVID-19 is an infectious disease caused by a newly discovered strain of SARS CoV2. The outbreak of this disease is significantly more prominent than the prior pandemic of SARS and MERS. Within three months, COVID-19 spread rapidly from China to the entire world. This disease affects the respiratory, digestive (Xiao et al., 2020), liver(J. Li \& Fan, 2020), eye (Wu et al., 2020)and central nervous(Li et al., 2020) systems of humans. Current pandemics of COVID19 call for urgent therapeutic treatment to minimize morbidity and protect the health of people at high risk of infection, especially when no specific treatment exists, (Poston et al., 2020). Use of antiviral drugs(Mitjà \& Clotet, 2020), anti-malaria drug(Liu et al., 2020) and companied therapy(Gautret et al., 2020)) are in practice in the absence of specific therapy (Jaffe, 2020).

Proteases represents potential target for the inhibition of $\mathrm{CoV}$ replication, newly released 3D crystal structure of SARS-CoV-2 main protease has $96 \%$ sequential identity with SARS CoV, and it has a few point mutations. These mutations may disrupt important hydrogen bonds and alter the receptor-binding site (ul Qamar et al., 2020). Several studies have been conducted on the use of the synthetic compound (Kumar et al., 2020), natural therapy against the $3 \mathrm{CL}^{\text {pro }}$ (Das et al., 
2020; Khaerunnisa et al., 2020) to stop the viral replication. Studies targeting spike protein to stop the viral attachment to the host cell are also underway (Maurya \& Sharma, 2020; Yan et al., 2020). Other complementary therapies reported for boosting host immune system (Jayawardena et al., 2020; Tillu et al., 2020). This present study explored in silico, the inhibitory effect of GA of GS against SARS-CoV-2 3CLpro. (H.-M. Liu et al., 1992). The ADME studies show the (table) drug-likeness of the compound. The docking studies show the excellent binding energy and the GS molecule binding with 3CLpro binding with specific amino acids in the pockets (Fig:3 and Table:2 ). The GMG bind to the domain I, II, and domain II-III linker of 3CL protein in with Hbond, pi-pi, and hydrophobic interactions. We have compared our results with the approved antiviral drug and some published natural compounds. However, the GA shows good binding energy compared to other molecules (supplementary data given in table S1).

MD simulations studies have contacted to support docking performance; several reports are available for the role of MD simulations (Boukharta et al., 2011; Hospital et al., 2015). There are many considerations, such as ligand conformation, water molecules, ions, cofactors, ligand protonation, conformational and salvation entropies, which could have an unpredictable impact on in silico predictions. MD simulations contacted for mainly GMG, which was found in high amount in a blood sample after the oral administration of GS extract. This could be because of the hydrolysis of all GA from GS extract in the gastrointestinal tract or first-pass hepatic metabolism (Kamble et al., 2013). The other GA molecule may be present in a limited amount in circulation. An earlier study has conducted MD stimulation for natural compound up 50 ns only (ul Qamar et al., 2020). We have done this at the max of $100 \mathrm{~ns}$, Entire simulation the average RMSD and RMSF values for backbone, $\mathrm{C} \alpha$, and side-chain for GMG 3CLpro and un-ligated-3CLpro complexes observed within the range,(Fig:3 a,b) the earlier study contacted for the synthetic compound was also observed nearly same value for SARS-CoV-2 3CL ${ }^{\text {pro }}$ (Kumar et al., 2020). GMG has shown the hydrogen bond interacted with amnion acid residues THR_24, THR_26, GLU_166, LEU_167 and PRO_168 in the docking study but in the simulation, it was observed the strong interaction however only with HIS_41 in the pocket atom other 2 strong interaction was observed in the connecting molecules GLN_ 189, GLN_192 during MD simulation. rGYR is a measure of protein compactness, stability, and folding, and the findings suggest normal behavior for GMG; both remained compact and stable during the $100 \mathrm{~ns}$ simulations. The existence of stabilizing intHBs generally discussed based on thermodynamics. IntHBs could stabilize the bioactive conformation of the ligand. This could reduce the conformational and translational entropy when binding and result in a stronger association (Sakamoto et al., 2014; Yunta, 2017). In this study, we found the one stable intHBs throughout the simulation, and the GMG torsion profile was also observed well throughout the 100ns simulation.

\section{Conclusion:}

The present study elucidates the possible roles of bioactive molecules of G. sylvestere, mainly GA as a ligand binding with a 3CLpro as a COVID-19 related target. Simulation studies show strong interactions up to $100 \mathrm{~ns}$. In addition, water molecules within the protein binding site indicated the stability of the GMG-3CLpro complex. RMSD and Ligand-RMSF percentage for C $\alpha$ showed that torsional analysis confirmed stability of GMG-3CLpro complex and protein-bound conformation. GA's ADMET properties were estimated to be non-toxic and biodegradable, making it desirable for human use. The results of this study not only demonstrate GS molecule's drug likeliness, but also provide a possible scientific indication of its likely modes of action. Further pharmacological studies to confirm the results of MD simulation in in-vitro models should 
also be encouraged to validate the use of this very important medicinal herb. Our study underlines the importance of GS as a potent medication for COVID-19.

\section{Author contribution:}

Subramani SK, designed and performed the docking the study. Gupta Y, Manish performed the MD stimulation. Subramani SK, Prasad GBKS wrote the manuscript. All authors reviewed, edited, and approved the final version of the manuscript.

\section{Conflict of interest:}

The authors declare that there is no conflict of interest associated with this manuscript.

\section{Reference:}

Amanat, F., \& Krammer, F. (2020). SARS-CoV-2 vaccines: status report. Cell, 1-7. https://doi.org/10.1016/j.immuni.2020.03.007

Andrusier, N., Nussinov, R., \& Wolfson, H. J. (2007). FireDock: fast interaction refinement in molecular docking. Proteins, 69(1), 139-159. https://doi.org/10.1002/prot.21495

Arora, D. S., \& Sood, H. (2017). In vitro antimicrobial potential of extracts and phytoconstituents from Gymnema sylvestre R.Br. leaves and their biosafety evaluation. AMB Express, 7(1), 115. https://doi.org/10.1186/s13568-017-0416-z

Arun, L. B., Arunachalam, A. M., Arunachalam, K. D., Annamalai, S. K., \& Kumar, K. A. (2014). In vivo anti-ulcer, anti-stress, anti-allergic, and functional properties of Gymnemic Acid Isolated from Gymnema sylvestre $\mathrm{R}$ Br. BMC Complementary and Alternative Medicine, 14(1), 70. https://doi.org/10.1186/1472-6882-14-70

Assiri, A., Abedi, G. R., Bin Saeed, A. A., Abdalla, M. A., Al-Masry, M., Choudhry, A. J., Lu, X., Erdman, D. D., Tatti, K., Binder, A. M., Rudd, J., Tokars, J., Miao, C., Alarbash, H., Nooh, R., Pallansch, M., Gerber, S. I., \& Watson, J. T. (2016). Multifacility outbreak of middle east respiratory syndrome in Taif, saudi Arabia. Emerging Infectious Diseases, 22(1), 32-40. https://doi.org/10.3201/eid2201.151370

Boukharta, L., Keränen, H., Stary-Weinzinger, A., Wallin, G., De Groot, B. L., \& Åqvist, J. (2011). Computer simulations of structure-activity relationships for hERG channel blockers. Biochemistry, 50(27), 6146-6156. https://doi.org/10.1021/bi200173n

Chan, J. F. W., Yuan, S., Kok, K. H., To, K. K. W., Chu, H., Yang, J., Xing, F., Liu, J., Yip, C. C. Y., Poon, R. W. S., Tsoi, H. W., Lo, S. K. F., Chan, K. H., Poon, V. K. M., Chan, W. M., Ip, J. D., Cai, J. P., Cheng, V. C. C., Chen, H., ... Yuen, K. Y. (2020). A familial cluster of pneumonia associated with the 2019 novel coronavirus indicating person-to-person transmission: a study of a family cluster. The Lancet, 395(10223), 514-523. https://doi.org/10.1016/S0140-6736(20)30154-9

Chhikara, B., Rathi, B., Singh, J., \& Poonam. (2020). Corona virus SARS-CoV-2 disease COVID-19: Infection, prevention and clinical advances of the prospective chemical drug therapeutics. Chemical Biology Letters, 7.

Corman, V. M., Landt, O., Kaiser, M., Molenkamp, R., Meijer, A., Chu, D. K. W., Bleicker, T., Brünink, S., Schneider, J., Schmidt, M. L., Mulders, D. G. J. C., Haagmans, B. L., Van Der Veer, B., Van Den Brink, S., Wijsman, L., Goderski, G., Romette, J. L., Ellis, J., Zambon, M., ... Drosten, C. (2020). Detection of 2019 novel coronavirus (2019-nCoV) by real-time RT-PCR. Eurosurveillance, 25(3). https://doi.org/10.2807/1560-7917.ES.2020.25.3.2000045 
Daina, A., Michielin, O., \& Zoete, V. (2017). SwissADME: A free web tool to evaluate pharmacokinetics, drug-likeness and medicinal chemistry friendliness of small molecules. Scientific Reports, 7. https://doi.org/10.1038/srep42717

Das, S., Sarmah, S., Lyndem, S., \& Singha Roy, A. (2020). An Investigation into the Identification of Potential Inhibitors of SARS-CoV-2 Main Protease Using Molecular Docking Study. https://doi.org/10.26434/CHEMRXIV.12129513.V1

Fehr, A. R., \& Perlman, S. (2015). Coronaviruses: An overview of their replication and pathogenesis. In Coronaviruses: Methods and Protocols (Vol. 1282, pp. 1-23). Springer New York. https://doi.org/10.1007/978-1-4939-2438-7_1

Gautret, P., Lagier, J.-C., Parola, P., Hoang, V. T., Meddeb, L., Mailhe, M., Doudier, B., Courjon, J., Giordanengo, V., Vieira, V. E., Dupont, H. T., Honoré, S., Colson, P., Chabrière, E., La Scola, B., Rolain, J.-M., Brouqui, P., \& Raoult, D. (2020). Hydroxychloroquine and azithromycin as a treatment of COVID-19: results of an open-label non-randomized clinical trial. International Journal of Antimicrobial Agents, 105949. https://doi.org/10.1016/j.ijantimicag.2020.105949

Gul, S., Ozcan, O., Asar, S., Okyar, A., Barıs, I., \& Kavakli, I. H. (2020). In Silico Identification of Widely Used and Well Tolerated Drugs That May Inhibit SARSCov- 2 3C-like Protease and Viral RNADependent RNA Polymerase Activities, and May Have Potential to Be Directly Used in Clinical Trials. https://doi.org/10.26434/CHEMRXIV.12123204.V1

Hanwell, M. D., Curtis, D. E., Lonie, D. C., Vandermeersch, T., Zurek, E., \& Hutchison, G. R. (2012). Avogadro: an advanced semantic chemical editor, visualization, and analysis platform. Journal of Cheminformatics, 4(1), 17. https://doi.org/10.1186/1758-2946-4-17

Herrewegh, A. A. P. M., Smeenk, I., Horzinek, M. C., Rottier, P. J. M., \& de Groot, R. J. (1998). Feline Coronavirus Type II Strains 79-1683 and 79-1146 Originate from a Double Recombination between Feline Coronavirus Type I and Canine Coronavirus. Journal of Virology, 72(5), 4508 LP - 4514.

Hospital, A., Goñi, J. R., Orozco, M., \& Gelpí, J. L. (2015). Molecular dynamics simulations: Advances and applications. In Advances and Applications in Bioinformatics and Chemistry (Vol. 8, Issue 1, pp. 37-47). Dove Medical Press Ltd. https://doi.org/10.2147/AABC.S70333

Huang, C., Wang, Y., Li, X., Ren, L., Zhao, J., Hu, Y., Zhang, L., Fan, G., Xu, J., Gu, X., Cheng, Z., Yu, T., Xia, J., Wei, Y., Wu, W., Xie, X., Yin, W., Li, H., Liu, M., .. Cao, B. (2020). Clinical features of patients infected with 2019 novel coronavirus in Wuhan, China. The Lancet, 395(10223), 497-506. https://doi.org/10.1016/S0140-6736(20)30183-5

Imoto, T., Miyasaka, A., Ishima, R., \& Akasaka, K. (1991). A novel peptide isolated from the leaves of Gymnema sylvestre-I. Characterization and its suppressive effect on the neural responses to sweet taste stimuli in the rat. Comparative Biochemistry and Physiology Part A: Physiology, 100(2), 309314. https://doi.org/10.1016/0300-9629(91)90475-R

Jaffe, S. (2020). Regulators split on antimalarials for COVID-19. Lancet (London, England), 395(10231), 1179. https://doi.org/10.1016/S0140-6736(20)30817-5

Jayawardena, R., Sooriyaarachchi, P., Chourdakis, M., Jeewandara, C., \& Ranasinghe, P. (2020). Enhancing immunity in viral infections, with special emphasis on COVID-19: A review. Diabetes and Metabolic Syndrome: Clinical Research and Reviews, 14(4), 367-382. https://doi.org/10.1016/j.dsx.2020.04.015

Kamble, B., Gupta, A., Patil, D., Khatal, L., Janrao, S., Moothedath, I., \& Duraiswamy, B. (2013). Determination of gymnemagenin in rat plasma using high-performance liquid chromatographytandem mass spectrometry: application to pharmacokinetics after oral administration of Gymnema sylvestre extract. Biomedical Chromatography, 27(5), 669-675. https://doi.org/10.1002/bmc.2845

Kang, M.-H., Lee, M. S., Choi, M.-K., Min, K.-S., \& Shibamoto, T. (2012). Hypoglycemic activity of Gymnema sylvestre extracts on oxidative stress and antioxidant status in diabetic rats. Journal of Agricultural and Food Chemistry, 60(10), 2517-2524. https://doi.org/10.1021/jf205086b 
Khaerunnisa, S., Kurniawan, H., Awaluddin, R., \& Suhartati, S. (2020). Potential Inhibitor of COVID-19 Main Protease ( M pro ) from Several Medicinal Plant Compounds by Molecular Docking Study. Preprints, March, 1-14. https://doi.org/10.20944/preprints202003.0226.v1

Komalavalli, N., \& Rao, M. V. (2000). In vitro micropropagation of Gymnema sylvestre - A multipurpose medicinal plant. Plant Cell, Tissue and Organ Culture, 61(2), 97-105. https://doi.org/10.1023/A:1006421228598

Kumar, S., Sharma, P. P., Shankar, U., Kumar, D., Joshi, S. K., Pena, L., Durvasula, R., Kumar, A., Kempaiah, P., . P., \& Rathi, B. (2020). Discovery of New Hydroxyethylamine Analogs Against 3CLpro Protein Target of SARS-CoV-2: Molecular Docking, Molecular Dynamics Simulation and Structure-Activity Relationship Studies. https://doi.org/10.26434/CHEMRXIV.12083004.V1

Li, J., \& Fan, J.-G. (2020). Characteristics and Mechanism of Liver Injury in 2019 Coronavirus Disease. Journal of Clinical and Translational Hepatology, 8(1), 1-5. https://doi.org/10.14218/jcth.2020.00019

Li, J. Y., You, Z., Wang, Q., Zhou, Z. J., Qiu, Y., Luo, R., \& Ge, X. Y. (2020). The epidemic of 2019novel-coronavirus (2019-nCoV) pneumonia and insights for emerging infectious diseases in the future. Microbes and Infection, 22(2), 80-85. https://doi.org/10.1016/j.micinf.2020.02.002

Li, Yan-Chao, Bai, W., \& Hashikawa, T. (2020). The neuroinvasive potential of SARS-CoV2 may play a role in the respiratory failure of COVID-19 patients. Journal of Medical Virology, 92(6), 552-555. https://doi.org/10.1002/jmv.25728

Li, Yan, \& Xia, L. (2020). Coronavirus Disease 2019 (COVID-19): Role of Chest CT in Diagnosis and Management. American Journal of Roentgenology, 1-7. https://doi.org/10.2214/ajr.20.22954

Li, Z., Yi, Y., Luo, X., Xiong, N., Liu, Y., Li, S., Sun, R., Wang, Y., Hu, B., Chen, W., Zhang, Y., Wang, J., Huang, B., Lin, Y., Yang, J., Cai, W., Wang, X., Cheng, J., Chen, Z., ... Ye, F. (2020). Development and Clinical Application of A Rapid IgM-IgG Combined Antibody Test for SARS-CoV-2 Infection Diagnosis. Journal of Medical Virology. https://doi.org/10.1002/jmv.25727

Liu, H.-M., Kiuchi, F., \& Tsuda, Y. (1992). Isolation and Structure Elucidation of Gymnemic Acids, Antisweet Principles of Gymnema sylvestre. CHEMICAL \& PHARMACEUTICAL BULLETIN, 40(6), 1366-1375. https://doi.org/10.1248/cpb.40.1366

Liu, J., Cao, R., Xu, M., Wang, X., Zhang, H., Hu, H., Li, Y., Hu, Z., Zhong, W., \& Wang, M. (2020). Hydroxychloroquine, a less toxic derivative of chloroquine, is effective in inhibiting SARS-CoV-2 infection in vitro. Cell Discovery, 6(1), 16. https://doi.org/10.1038/s41421-020-0156-0

Liu, X., Ye, W., Yu, B., Zhao, S., Wu, H., \& Che, C. (2004). Two new flavonol glycosides from Gymnema sylvestre and Euphorbia ebracteolata. Carbohydrate Research, 339(4), 891-895. https://doi.org/10.1016/j.carres.2003.12.017

Lu, R., Zhao, X., Li, J., Niu, P., Yang, B., Wu, H., Wang, W., Song, H., Huang, B., Zhu, N., Bi, Y., Ma, X., Zhan, F., Wang, L., Hu, T., Zhou, H., Hu, Z., Zhou, W., Zhao, L., ... Tan, W. (2020). Genomic characterisation and epidemiology of 2019 novel coronavirus: implications for virus origins and receptor binding. The Lancet, 395(10224), 565-574. https://doi.org/10.1016/S0140-6736(20)30251-8

Luhulima, F., Karyana, I., \& Sumadiono, S. (2016). Probiotic therapy on children with allergic rhinitis. Paediatrica Indonesiana, 53(5), 264. https://doi.org/10.14238/pi53.5.2013.264-7

Mahajan, S., Chauhan, P., Subramani, S. K., Anand, A., Borole, D., Goswamy, H., \& Prasad, G. B. K. S. (2015). Evaluation of "GSPF kwath": A Gymnema sylvestre-containing polyherbal formulation for the treatment of human type 2 diabetes mellitus. European Journal of Integrative Medicine, 7(3), 303-311. https://doi.org/10.1016/j.eujim.2015.01.003

Malik, J., Manvi, F. V, Alagawadi, K. R., \& Noolvi, M. (2008). Evaluation of anti-inflammatory activity of Gymnema sylvestre leaves extract in rats. International Journal of Green Pharmacy, 2(2), 114-115. https://doi.org/10.4103/0973-8258.41184 
Manohar, S. H., Naik, P. M., Praveen, N., \& Murthy, H. N. (2009). Distribution of gymnemic acid in various organs of Gymnema sylvestre. Journal of Forestry Research, 20(3), 268-270. https://doi.org/10.1007/s11676-009-0046-7

Mashiach, E., Schneidman-Duhovny, D., Andrusier, N., Nussinov, R., \& Wolfson, H. J. (2008). FireDock: a web server for fast interaction refinement in molecular docking. Nucleic Acids Research, 36(Web Server), W229--W232. https://doi.org/10.1093/nar/gkn186

Maurya, D., \& Sharma, D. (2020). Evaluation of Traditional Ayurvedic Preparation for Prevention and Management of the Novel Coronavirus (SARS-CoV-2) Using Molecular Docking Approach. https://doi.org/10.26434/CHEMRXIV.12110214.V1

Mitjà, O., \& Clotet, B. (2020). Use of antiviral drugs to reduce COVID-19 transmission. In The Lancet Global Health (Vol. 0, Issue 0). Elsevier Ltd. https://doi.org/10.1016/S2214-109X(20)30114-5

Owen, C. D., Lukacik, P., Strain-Damerell, C.M. Douangamath, A., Powell, A. J., Fearon, D., BrandaoNeto, J., Crawshaw, A. D., Aragao, D., Williams, M., Flaig, R., Hall, D. R., McAuley, K. E., Mazzorana, M., Stuart, D. I., von Delft, F., \& Walsh, M. A. (2020). COVID-19 main protease with unliganded active site (2019-nCoV, coronavirus disease 2019, SARS-CoV-2). RCSB Protein Data Bank (PDB) ID: 6Y84, 3-7. https://doi.org/10.2210/pdb6Y84

Pene, F., Merlat, A., Vabret, A., Rozenberg, F., Buzyn, A., Dreyfus, F., Cariou, A., Freymuth, F., \& Lebon, P. (2003). Coronavirus 229E-Related Pneumonia in Immunocompromised Patients. Clinical Infectious Diseases, 37(7), 929-932. https://doi.org/10.1086/377612

Pires, D. E. V., Blundell, T. L., \& Ascher, D. B. (2015). pkCSM: Predicting small-molecule pharmacokinetic and toxicity properties using graph-based signatures. Journal of Medicinal Chemistry, 58(9), 4066-4072. https://doi.org/10.1021/acs.jmedchem.5b00104

Poston, J. T., Patel, B. K., \& Davis, A. M. (2020). Management of Critically Ill Adults With COVID-19. JAMA, E1-E3. https://doi.org/10.1001/jama.2020.4914

Raju, V. S. R., Kannababu, S., \& Subbaraju, G. V. (2006). Standardisation of Gymnema sylvestre R.Br. by high-performance thin-layer chromatography: An improved method. Phytochemical Analysis, 17(3), 192-196. https://doi.org/10.1002/pca.905

Rao, S. G., Joseph, S. E., \& Kenneth, C. W. (1974). Antiviral activity of triterpenoid saponins containing acylated $\beta$-amyrin aglycones. Journal of Pharmaceutical Sciences, 63(3), 471-473. https://doi.org/10.1002/jps.2600630341

Sahu, N. P., Mahato, S. B., Sarkar, S. K., \& Poddar, G. (1996). Triterpenoid saponins from Gymnema Sylvestre. Phytochemistry, 41(4), 1181-1185. https://doi.org/10.1016/0031-9422(95)00782-2

Sakamoto, T., Koga, Y., Hikota, M., Matsuki, K., Murakami, M., Kikkawa, K., Fujishige, K., Kotera, J., Omori, K., Morimoto, H., \& Yamada, K. (2014). Design and synthesis of novel 5-(3,4,5trimethoxybenzoyl)-4-aminopyrimidine derivatives as potent and selective phosphodiesterase 5 inhibitors: Scaffold hopping using a pseudo-ring by intramolecular hydrogen bond formation. Bioorganic and Medicinal Chemistry Letters, 24(22), 5175-5180. https://doi.org/10.1016/j.bmcl.2014.09.082

Schneidman-Duhovny, D., Inbar, Y., Nussinov, R., \& Wolfson, H. J. (2005). Geometry-based flexible and symmetric protein docking. Proteins: Structure, Function and Genetics, 60(2), 224-231. https://doi.org/10.1002/prot.20562

Schrödinger Release. (2019). Desmond Molecular Dynamics System. Schrödinger LLC.

Singh, V. K., Dwivedi, P., Chaudhary, B. R., \& Singh, R. (2015). Immunomodulatory Effect of Gymnema sylvestre (R.Br.) Leaf Extract: An In Vitro Study in Rat Model. PloS One, 10(10), e0139631. https://doi.org/10.1371/journal.pone.0139631

Tillu, G., Chaturvedi, S., Chopra, A., \& Patwardhan, B. (2020). Public Health Approach of Ayurveda and Yoga for COVID-19 Prophylaxis. The Journal of Alternative and Complementary Medicine, acm.2020.0129. https://doi.org/10.1089/acm.2020.0129 
ul Qamar, M. T., Alqahtani, S. M., Alamri, M. A., \& Chen, L.-L. (2020). Structural basis of SARS-CoV-2 3CLpro and anti-COVID-19 drug discovery from medicinal plants. Journal of Pharmaceutical Analysis. https://doi.org/10.1016/j.jpha.2020.03.009

WHO. (2020a). Coronavirus disease 2019 (COVID-19) Situation Report - 120. https://www.who.int/docs/default-source/coronaviruse/situation-reports/20200519-covid-19-sitrep120.pdf?sfvrsn=515cabfb_2

WHO. (2020b). Coronavirus Disease 2019 COVID-19.

Woo, P. C. Y., Huang, Y., Lau, S. K. P., \& Yuen, K. Y. (2010). Coronavirus genomics and bioinformatics analysis. In Viruses (Vol. 2, Issue 8, pp. 1805-1820). MDPI AG. https://doi.org/10.3390/v2081803

Wu, P., Duan, F., Luo, C., Liu, Q., Qu, X., Liang, L., \& Wu, K. (2020). Characteristics of Ocular Findings of Patients With Coronavirus Disease 2019 (COVID-19) in Hubei Province, China. JAMA Ophthalmology. https://doi.org/10.1001/jamaophthalmol.2020.1291

Xiao, F., Tang, M., Zheng, X., Liu, Y., Li, X., \& Shan, H. (2020). Evidence for Gastrointestinal Infection of SARS-CoV-2. Gastroenterology. https://doi.org/10.1053/j.gastro.2020.02.055

Yan, Y.-M., Shen, X., Cao, Y.-K., Zhang, J.-J., Wang, Y., \& Cheng, Y.-X. (2020). Discovery of Anti2019-nCoV Agents from Chinese Patent Drugs via Docking Screening. Preprint. https://doi.org/10.20944/preprints202002.0254.v1

Yang, K., Wang, F., Chen, C., \& Yang, H. (2015). Crystal Structure of Human Coronavirus NL63 Main Protease in Complex With an Inhibitor. Open Forum Infectious Diseases, 2(suppl_1). https://doi.org/10.1093/ofid/ofv131.163

Yasukawa, K., Okuda, S., \& Nobushi, Y. (2014). Inhibitory Effects of Gymnema ( Gymnema sylvestre ) Leaves on Tumour Promotion in Two-Stage Mouse Skin Carcinogenesis. Evidence-Based Complementary and Alternative Medicine, 2014, 1-5. https://doi.org/10.1155/2014/328684

YOSHIKAWA, M., MURAKAMI, T., KADOYA, M., LI, Y., MURAKAMI, N., YAMAHARA, J., \& MATSUDA, H. (1997). Medicinal Foodstuffs. IX. The Inhibitors of Glucose Absorption from the Leaves of Cymnema sylvestre R. BR. (Asclepiadaceae): Structures of Gymnemosides a and b. CHEMICAL \& PHARMACEUTICAL BULLETIN, 45(10), 1671-1676. https://doi.org/10.1248/cpb.45.1671

Yunta, J. R. M. (2017). It Is Important to Compute Intramolecular Hydrogen Bonding in Drug Design? American Journal of Modeling and Optimization, 5(1), 24-57. https://doi.org/10.12691/ajmo-5-1-3 


\begin{tabular}{|l|l|l|l|}
\hline \multicolumn{2}{|c|}{ Table 1 : Bioactive compounds of GS } \\
\hline S.no & phytoconstituents & Classification & Reference \\
\hline 1 & Triterpene saponins & Gymnemic acids 1,2,3,4 and DGA & (H.-M. Liu et al., 1992) \\
\hline 2 & Oleanane saponins & Gymnemsaponins & $\begin{array}{l}\text { (YOSHIKAWA et al., } \\
\text { 1997) }\end{array}$ \\
\hline 3 & Dammarene saponins & Gymnemosides a, b, c, d, e, and f & $\begin{array}{l}\text { (YOSHIKAWA et al., } \\
\text { 1997) }\end{array}$ \\
\hline 4 & Gurmarin & A novel 35-amino-acid peptide & (Imoto et al., 1991) \\
\hline 5 & Triterpenoid saponins & Gymnemasins A to D & (Sahu et al., 1996) \\
\hline 6 & $\begin{array}{l}\text { Gymnemanol } \\
\text { (aglycone) }\end{array}$ & & $\begin{array}{l}\text { (Sahu et al., 1996) } \\
\text { (YOSHIKAWA et al., } \\
\text { 1997) }\end{array}$ \\
\hline 7 & Gymmestrogenin & Pentahydroxytriterpene & (X. Liu et al., 2004) \\
\hline 8 & Flavonol glycoside & Kaempferol & \\
\hline
\end{tabular}




\begin{tabular}{|c|c|c|c|c|c|c|}
\hline Property Name & GA1 & GA2 & GA3 & GA4 & DGA & GMG \\
\hline Pubchem ID & 11953919 & 91617872 & 14264066 & 14264063 & 44144284 & 10051937 \\
\hline Structure of the compound & & & & & & \\
\hline Formula & $\mathrm{C} 43 \mathrm{H} 66 \mathrm{O} 14$ & C43H68O14 & $\mathrm{C} 41 \mathrm{H} 66 \mathrm{O} 13$ & C41H64O13 & $\mathrm{C} 36 \mathrm{H} 58 \mathrm{O} 12$ & $\mathrm{C} 30 \mathrm{H} 50 \mathrm{O} 6$ \\
\hline Molecular Weight (g/mol) & 807 & 809 & 767 & 764.9 & 682.8 & 506.7 \\
\hline XLogP3-AA & 3.9 & 4.1 & 4 & 3.8 & 2.1 & 4 \\
\hline Hydrogen Bond Donor & 7 & 7 & 8 & 8 & 9 & 6 \\
\hline Hydrogen Bond Acceptor Count & 14 & 14 & 13 & 13 & 12 & 6 \\
\hline Rotatable Bond Count & 10 & 11 & 9 & 8 & 5 & 2 \\
\hline Topological Polar Surface Area $\left(\AA^{2}\right)$ & 230 & 230 & 224 & 224 & 218 & 121 \\
\hline Heavy Atom Count & 57 & 57 & 54 & 54 & 48 & 36 \\
\hline Violation of Lipinski's rule & 3 & 3 & 3 & 3 & 1 & 2 \\
\hline Bioavailability Score & 0.11 & 0.11 & 0.11 & 0.11 & 0.11 & 0.17 \\
\hline $\begin{array}{l}\text { Caco2 permeability } \\
\left(\log \text { Papp in } 10^{-6} \mathrm{~cm} / \mathrm{s}\right)\end{array}$ & 0.695 & 0.69 & -0.412 & -0.395 & -0.534 & 0.496 \\
\hline P-glycoprotein substrate & Yes & Yes & Yes & Yes & Yes & Yes \\
\hline $\begin{array}{l}\text { Oral Rat Acute Toxicity (LD50) (log } \\
\mathrm{mg} / \mathrm{kg} \_ \text {bw/day) }\end{array}$ & 3.838 & 3.834 & 3.787 & 3.79 & 3.499 & 3.76 \\
\hline $\begin{array}{l}\text { Oral Rat Chronic Toxicity (LOAEL) } \\
\text { (log } \mathrm{mg} / \mathrm{kg} \_ \text {bw/day) }\end{array}$ & 3.073 & 3.075 & 3.382 & 3.38 & 3.882 & 2.64 \\
\hline Hepatotoxicity & No & No & No & No & No & No \\
\hline
\end{tabular}


Table 3 Molecular docking analysis of GS molecules with COVID - 19 main protease: 3CLpro (Pdb id :6y84)

\begin{tabular}{|c|c|c|c|c|c|c|c|}
\hline \multirow{2}{*}{$\begin{array}{l}\text { Compound } \\
\text { name }\end{array}$} & \multirow{2}{*}{$\begin{array}{l}\text { Global } \\
\text { Energy }\end{array}$} & \multirow{2}{*}{$\begin{array}{l}\text { Attractive } \\
\text { VWE }\end{array}$} & \multirow{2}{*}{$\begin{array}{l}\text { Repulsive } \\
\text { VWE }\end{array}$} & \multirow[t]{2}{*}{ ACE } & \multirow[t]{2}{*}{ ISM } & \multicolumn{2}{|c|}{ Protein ligand interaction } \\
\hline & & & & & & Hydrogen bonds & Hydrophobic bonds \\
\hline GA3 & -52.46 & -23.77 & 5.18 & -15.79 & 6.15 & $\begin{array}{l}\text { LEU_27,HIS_41, } \\
\text { GLY_143 CYS_145, } \\
\text { HIS_164, PRO_168, } \\
\text { ARG_188, GLN_189, } \\
\text { THR_190, ALA_191, } \\
\text { GLN192 }\end{array}$ & $\begin{array}{l}\text { MET_49, } \\
\text { MET_165, } \\
\text { LEU_167 }\end{array}$ \\
\hline GA4 & -52.17 & -27.15 & 19.82 & -18.89 & 4.20 & $\begin{array}{l}\text { THR_24, THR_26 } \\
\text { THR_44, THR_45 } \\
\text { HIS_164,MET-165 } \\
\text { GLU_166,LEU_167 } \\
\text { GLU_189, THR_190 } \\
\text { GLN_192 }\end{array}$ & HIIS-14,MET-49 \\
\hline DGA & -43.43 & -23.96 & 16.47 & -15.19 & 5.20 & $\begin{array}{l}\text { THR_24GLU_166, } \\
\text { THR_-190, GLN_192 }\end{array}$ & $\begin{array}{l}\text { HIS-14,MET-49 } \\
\text { MET } 165\end{array}$ \\
\hline GMG & -43.69 & -19.20 & 4.81 & -13.21 & 3.43 & $\begin{array}{l}\text { THR_25, THR_26 HIS } \\
\text { 41, CYS_44, THR_45, } \\
\text { GLN89, } \\
\text { LEU } 167\end{array}$ & $\begin{array}{l}\text { MET_49,MET_165 } \\
\text { PRO_168 }\end{array}$ \\
\hline
\end{tabular}

Note: VWE= Van der Waals Energy, ACE=Atomic Contact Energy, ISM= Insideness Measure 


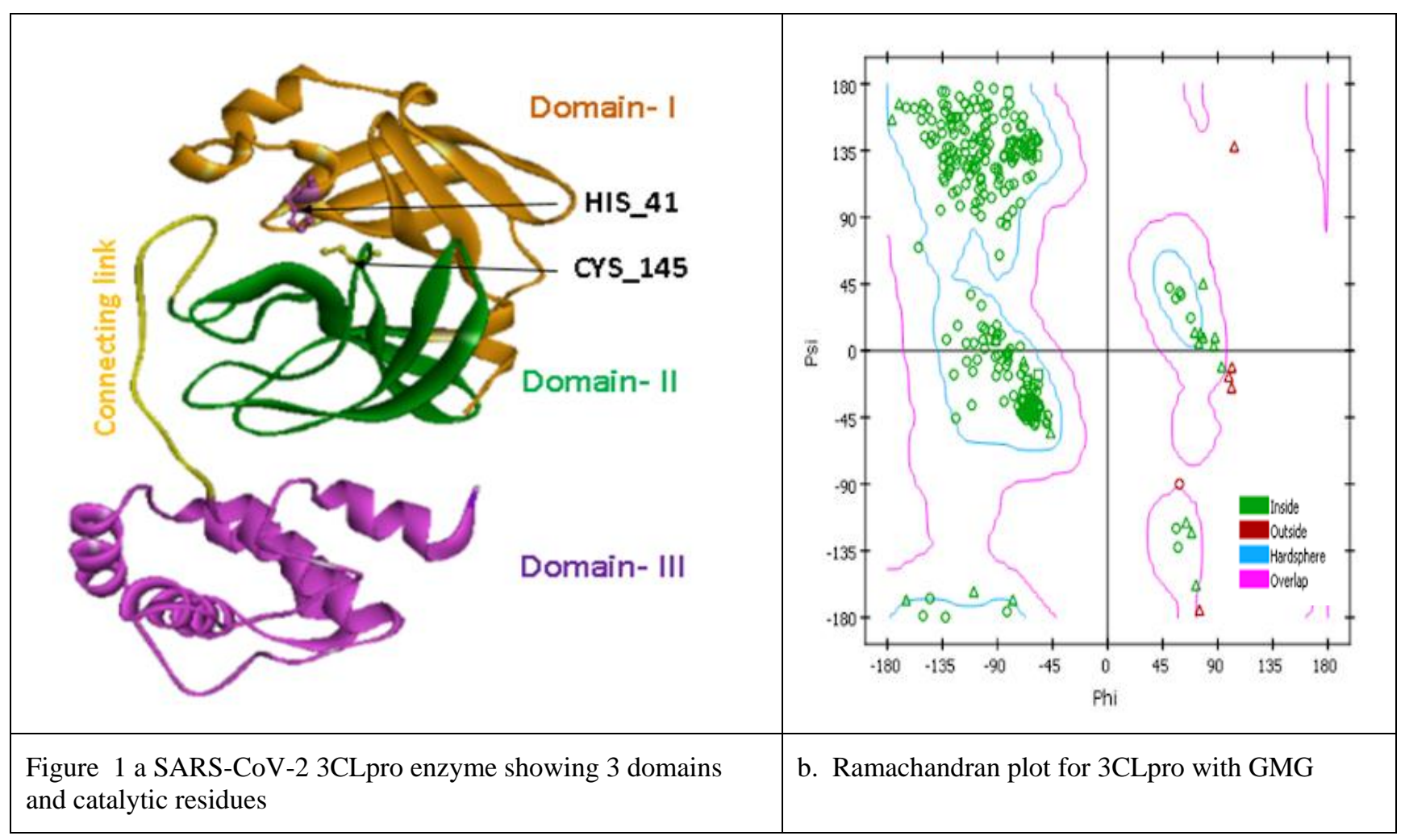




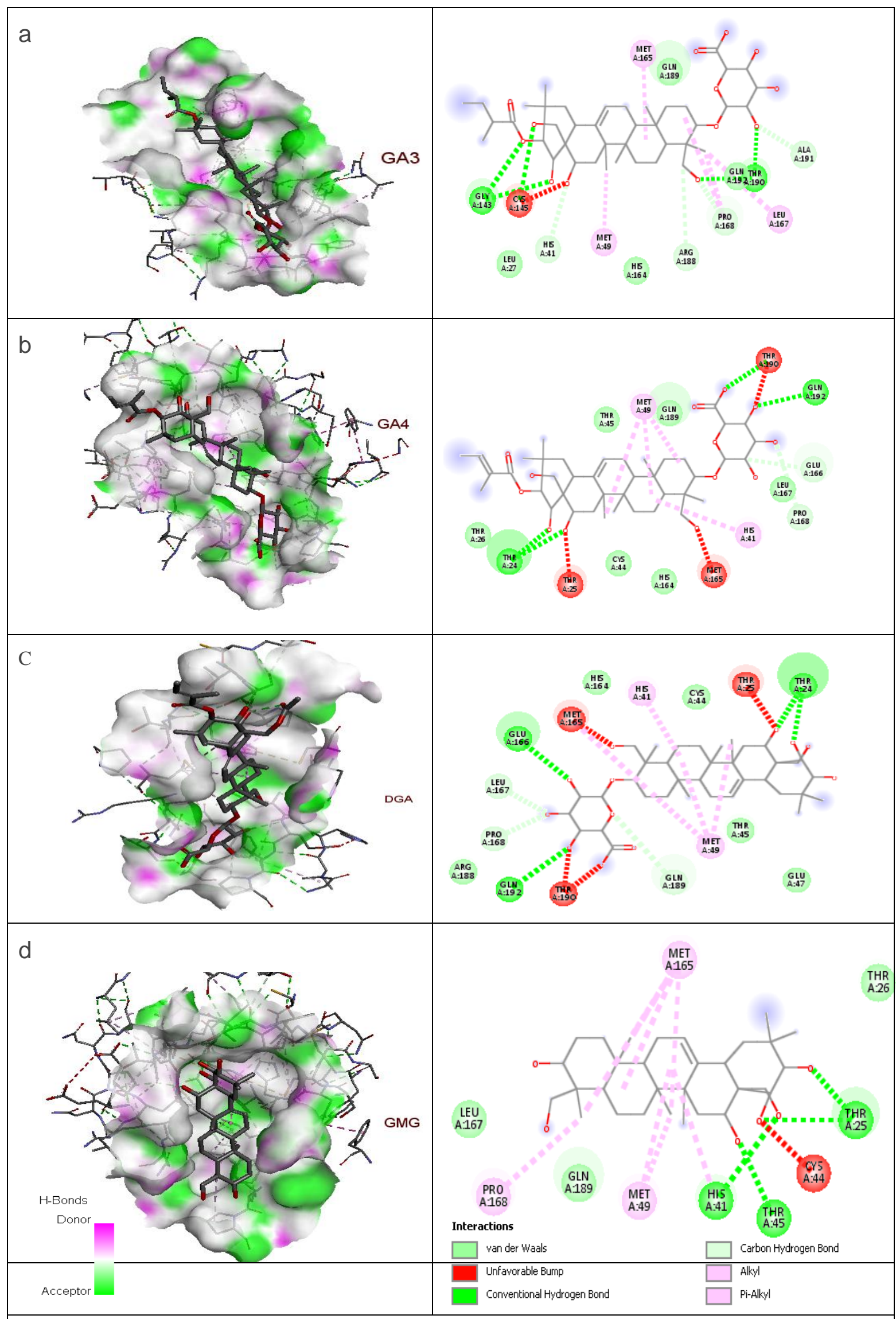

Figure2: Docking analysis visualization of 3CL Pro (6y84) binding with GS molecules 


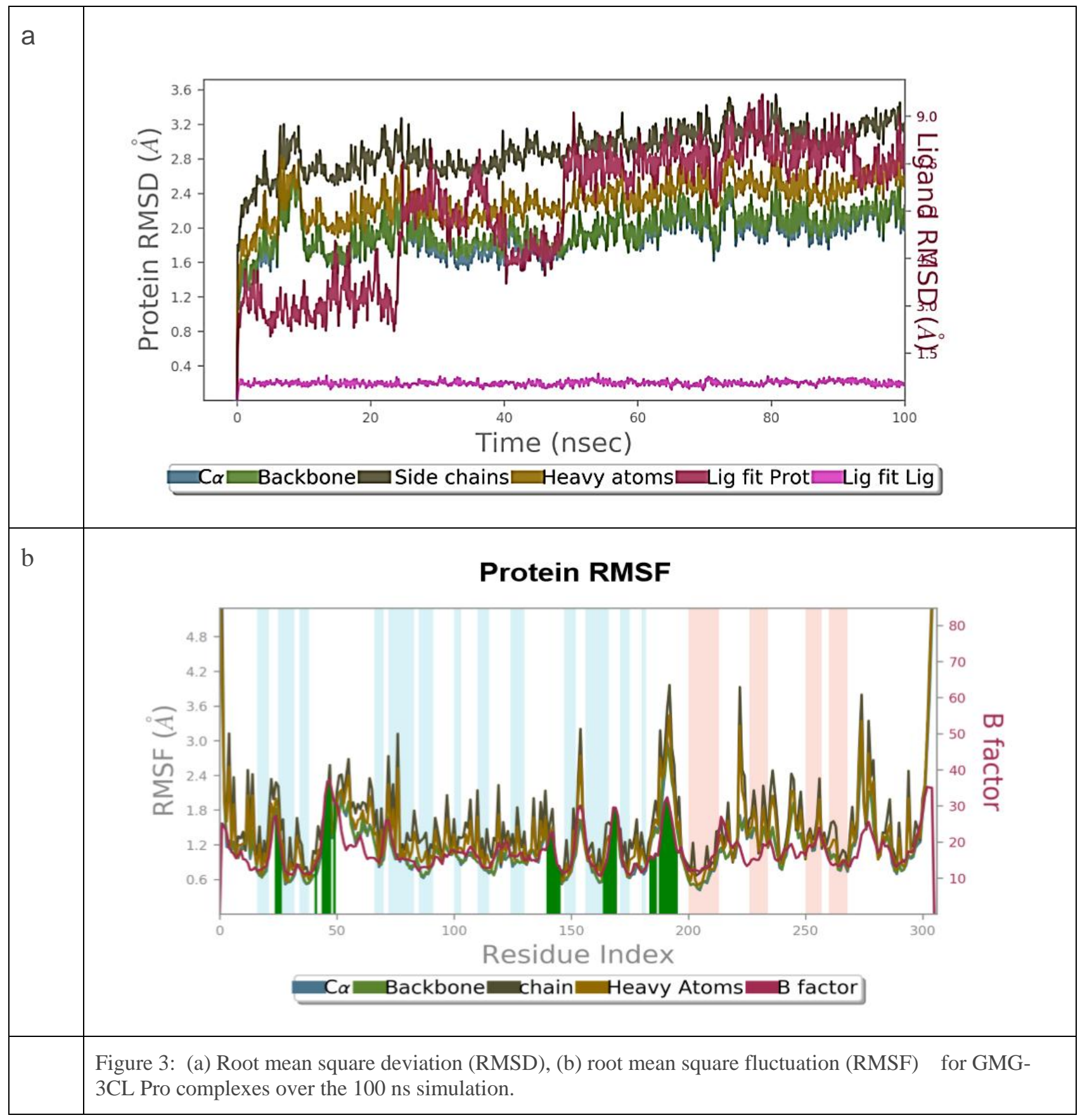




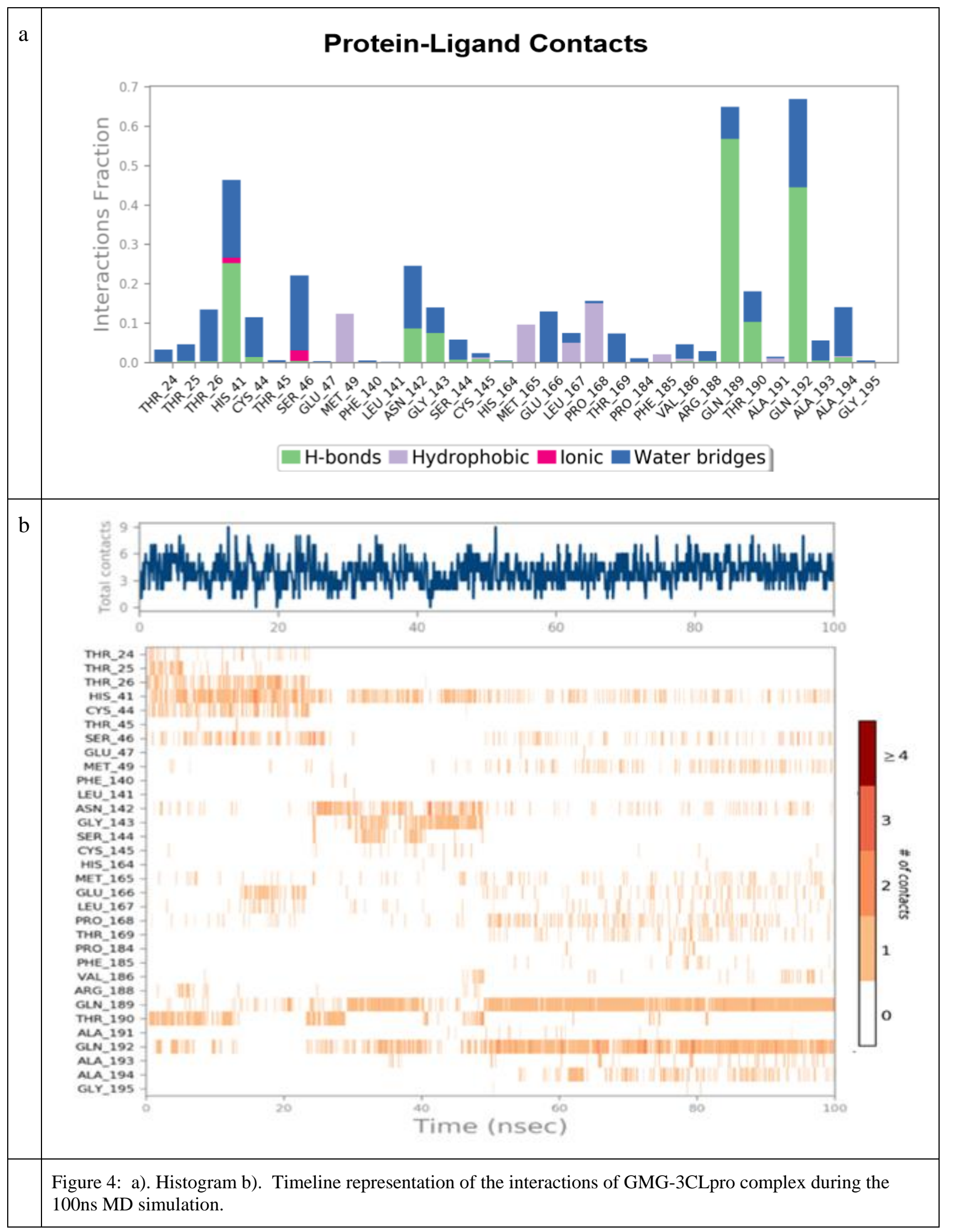




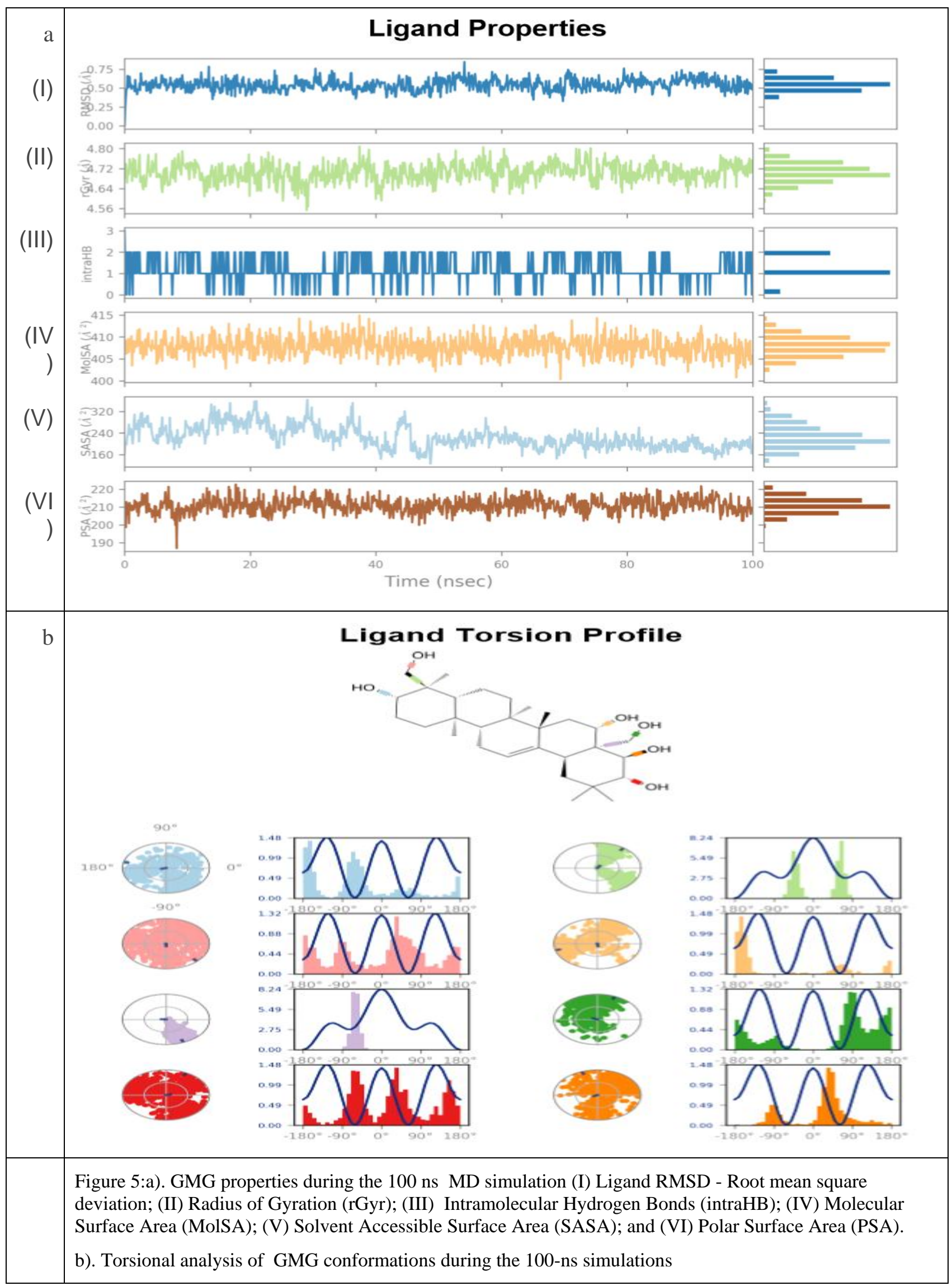




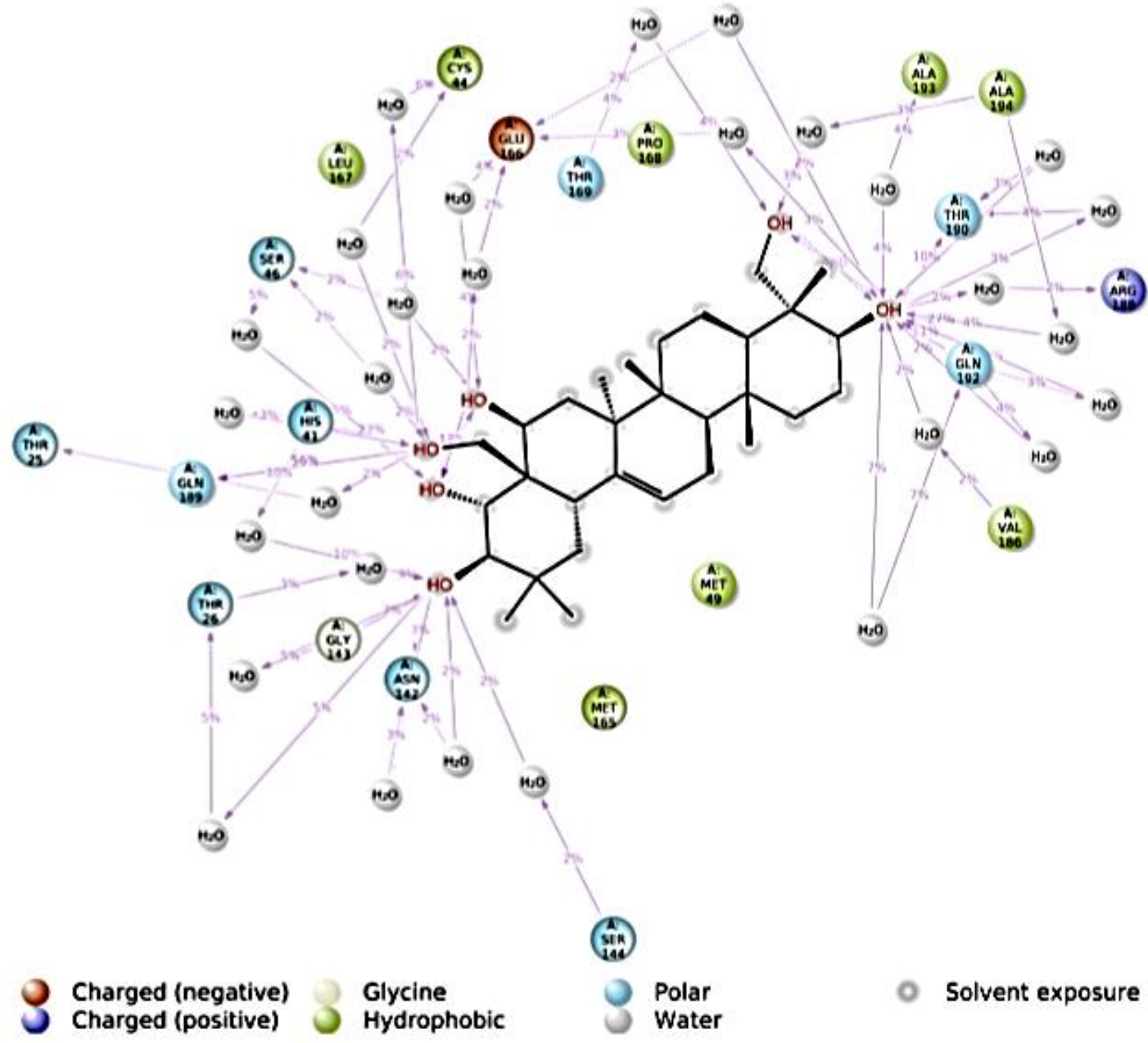




\section{Supplementary}

S1:Reference and reported compound docked with same procedure

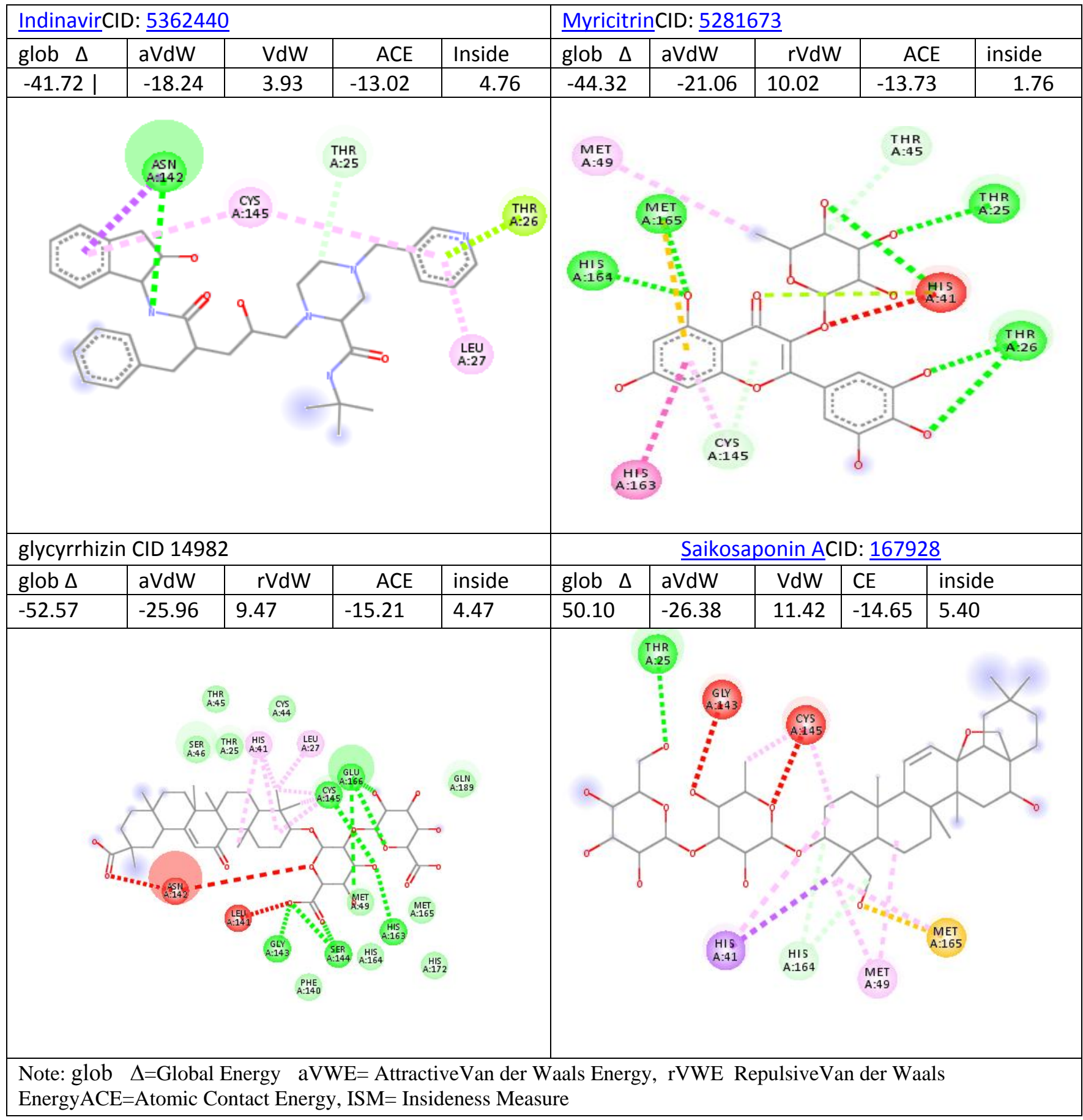

